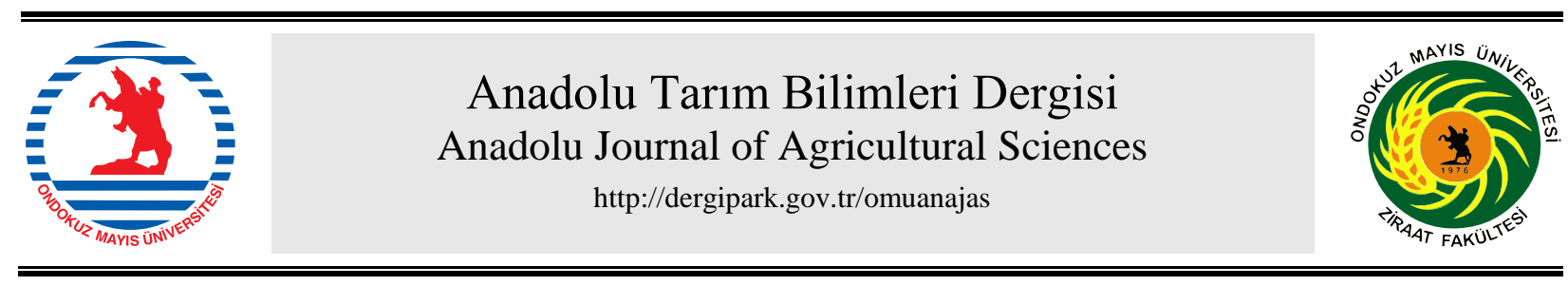

Araştırma/Research

\section{Konya koşullarında geliştirilmiş atdişi mısır hatlarının bazı agro-morfolojik ve fizyolojik özelliklerinin korelasyonu}

\author{
Elif Özdemir ${ }^{a *}$, Bayram Sade ${ }^{b}$ \\ ${ }^{a}$ Selçuk Üniversitesi, Ziraat Fakültesi, Tarla Bitkileri Bölümü, Kampüs/Konya \\ ${ }^{b}$ KTO Karatay Üniversitesi, İșletme Yönetim Bilimleri Fakültesi, Enerji Yönetimi Bölümü, Karatay/Konya \\ *Sorumlu yazar/corresponding author: elifyetim@ @elcuk.edu.tr \\ Geliş/Received 02/10/2018 Kabul/Accepted 24/01/2019
}

Anahtar Sözcükler: Fotosentetik unsurlar Islah Malondialdehit Prolin $\left(0.57^{* *}\right)$ özellikleri arasında çok önemli korelasyonlar belirlenirken yaprak dikliği $\times$ ilk koçan yüksekliği $(0.32 *)$, yaprak sayısı $\times$ ilk koçan yüksekliği $(0.32 *)$, yaprak alanı $\times$ fotosentetik verim $\left(0.29^{*}\right)$, yaprak alanı $\times$ malondialdehit $\left(-0.28^{*}\right)$ ve yaprak alanı $\times$ klorofil miktarı $\left(0.26^{*}\right)$ özellikleri arasında önemli ve anlamlı ikili ilişkiler olduğu belirlenmiştir. Bu çalışmada aralarında önemli korelasyonların belirlendiği karakterlerin birisinden yola çıkarak diğerleri ile ilgili bilgilere ulaşılabileceği, dolayısıyla daha az zaman, işgücü ve emek ile daha fazla veri üretilebileceği sonucuna ulaşı1mıştır.

Correlation of some of agro - morphological and physiological traits in maize inbred lines developed in Konya conditions

\begin{abstract}
The trial was conducted at Research and Application area of Selcuk University Agriculture Faculty during 2013 growing season. The seeds of 31 dent corn lines were used as materials and 12 agro morphological and physiological traits were investigated. All correlation combinations among the traits were calculated. According to the results very significant correlations were detected among first ear height $\times$ photosynthetic efficiency $\left(0.64^{* *}\right)$, leaf area $\times$ leaf angle $\left(0.57^{* *}\right)$, and significant correlations among leaf area $\times$ first ear height $\left(0.32^{*}\right)$, leaf number $\times$ first ear height $\left(0.32^{*}\right)$, leaf area $\times$ photosynthetic efficiency $\left(0.29^{*}\right)$, leaf area $\times$ malondialdehyde $\left(0.28^{*}\right)$ and leaf area $\times$ chlorophyll content $\left(0.26^{*}\right)$ traits. According to the results of the study it was observed that one of the characters with significant correlations can give knowledge to researchers about other correlated properties so more information can be produced with lower time and labour.
\end{abstract}

Keywords:

Photosyntetic

properties

Breeding

Malondialdehyde

Proline

(C) OMU ANAJAS 2019

\section{Giriş}

Dünyada üretim bakımından buğday (751 milyon ton) ve çeltiğin (482 milyon ton) izlediği mısır, yaklaşık bir milyar tonluk rekoltesiyle tahıllar içerisinde en fazla üretimi yapılan türü oluşturmaktadır. Yurdumuzda mısır üretimi 2016 yılında 2006 yllına göre \% 68' lik bir artışla 6.4 milyon ton olarak gerçekleşmiştir. Misır üretimindeki bu artışın en önemli nedeni; üretiminin yoğun olduğu bölgelerde hibrit tohum kullanımının yaygınlaşması, üretim tekniklerindeki gelişmeler, sulanabilir alanların artması ve bunlara bağlı olarak artan verimdir (Bayramoğlu ve Bozdemir, 2018). Mısırın geniş adaptasyon kabiliyeti ve yüksek verim potansiyeli sebebiyle hemen her bölgemizde tarımı yapılmaktadır (Ayrancı ve Sade, 2004). Mısır küresel dünyada insanların toplam kalori ihtiyacının \% 20' sini, tahıl kaynaklı gıdalardan alınan proteinin ise \% 15' ini karşılamaktadır (Musila ve ark., 2010). Bilhassa günümüzde hızla tırmanan nüfus artışı tarım alanlarını 
daraltmakta, sınırlı alanlardan yüksek verim almayı zorunlu hale getirmektedir. Bu tür durumlarda en etkili yaklaşım artan verimle birlikte ekim alanı ihtiyacının azaltılmasıdır. Üreticinin arzu ettiği özelliklere sahip yeni mısır çeşitlerinin geliştirilmesi misır islah çalışmalarının yoğun bir şekilde devam ettirilmesi ile mümkündür (Konuşkan, 2006). Al-Ghamdi (2009) yeni ve hızlı çeşit geliştirmede fizyolojik yaklaşımların çok daha etkili olacağını bildirmiştir. Islahta melezleme 1slahı önemli yer tutmaktadır. Uzun yıllar süren, yorucu ve pahalı bir yöntem olan melezleme 1slahında başarı, popülasyondan üzerinde çalışılan karakterin genetik yapısına uygun anaçların seçimi ile mümkündür (Temiz, 2004)

Mısırda verim ve kalite üzerine etkili çok sayıda agronomik, fizyolojik ve bitkisel özelliği tespit etmek büyük zaman, maliyet ve işgücü gerektirmekte, bunun yanında deneme parsellerindeki bitkiler bu tip çalışmalar esnasında zarar görebilmektedirler. Tüm bu sebepler nedeniyle araştırmacılar birbirleriyle sıkı ilişkisi olan özellikleri gruplandırmaya ve her gurubu temsil edebilecek özellikler üzerinde çalışmaya odaklanmışlardır (Sade ve ark., 2005). Özellikler veya değişkenler arasındaki doğrusal ilişkinin ölçüsü korelasyon katsayısıdır. İki değișken arasındaki korelasyon katsayısı yüksek ise bu iki değişkenin birbiri ile iliş̧kili olduğunu söylemek mümkündür (Erdal, 2016). Misırda birçok özellik çeşitli biyomorfolojik ve biyofizyolojik unsurların birbirleriyle olan etkileşimi ile oluşur. $\mathrm{Bu}$ nedenle bilhassa morfolojik unsurların ön planda olduğu ıslah çalışmalarında üzerinde çalışılan karakterler arasındaki ilişsinin ortaya konması ıslahçıya önemli avantajlar sağlar. Ülkemizde her y1l gerek yerel, gerekse yabancı kaynaklı hibrit mısır çeşitleri tescil edilmekte ve üreticiye sunulmaktadır. Islah çalışmaları; tarım alanlarında üreticinin ihtiyaçlarını karşılayacak nitelikte genotipler geliştirmeye olanak sağlaması, sslah materyallerinin özelliklerinin tanımlanması, bu karakterler arasındaki ilişkilerin belirlenmesi, üreticinin anlık ihtiyaçlarının etkili bir biçimde karşılanması ve gelecekteki ıslah çalışmalarına ışık tutması açısından son derece önemlidir.

\section{Materyal ve Yöntem}

Araştırmada materyal olarak, S.Ü.Z.F. Tarla Bitkileri Bölümü Öğretim Üyesi Prof. Dr. Bayram SADE ve ekibi tarafından geliştirilmiş, uzun süredir kendileme programları sürdürülmekte olan 31 adet atdişi mısır varyete grubuna ait durulmuş S7 saf hatlarından elde edilmiş tohumluklar kullanılmıştır. Tarla denemesi 2013 yılı yetiştirme sezonunda 1 yıl süreyle S.Ü.Z.F. Tarla Bitkileri Bölümü Prof. Dr. Abdülkadir AKÇİN Araştırma ve Uygulama çiftliğinde "Augmented Deneme Deseni" ne göre dört blok halinde yürütülmüştür (Petersen, 1994). Bloklarda her saf hat tekerrürsüz $5 \mathrm{~m}$ uzunluğunda bir sira ile temsil edilirken, standart hibrit misır çeşitleri [DKC 5783 (FAO 550), P 3394 (FAO 500)] her blokta tekrarlı olarak yer almışlardır. Deneme sıra arası $70 \mathrm{~cm}$, sıra üzeri ise $20 \mathrm{~cm}$ olacak şekilde kurgulanmıştır. Ekim mayıs ayının ilk haftası içerisinde el ile yapılmıştır. Denemenin yapılacağı alan ekim öncesi toprak işleme ile hazır hale getirilmiş, ortamdaki yabancı otlar mekanik olarak uzaklaştırılıp, tohum yatağı hazırlanmıştır. Deneme alanına toprak analiz sonuçları da dikkate alınarak, $18 \mathrm{~kg} \mathrm{da}^{-1} \mathrm{~N}$ ve $11 \mathrm{~kg} \mathrm{da}^{-1} \mathrm{P} 2 \mathrm{O} 5$ hesabıyla gübreleme yapılmıştır. Azotun $4 \mathrm{~kg} \mathrm{da}^{-1}$, 1 ve P' nin tamamı ekimle birlikte DAP (18 N - 46 P2O5) formunda uygulanmıştır. Azotun kalan kısmı ikinci çapa esnasında ve ilerleyen gelişme dönemlerinde parçalar halinde amonyum nitrat $\left(\begin{array}{llll}\% & 30 & \mathrm{~N}\end{array}\right)$ formunda uygulanmıştır. Deneme alanının sulanmasında damla sulama sistemi kullanılmış, sulama aralıkları bitkinin ihtiyaçları doğrultusunda belirlenmiştir. Gözlem, ölçüm ve analizler "Tepe Püskülü Çıkış" döneminde her bir parseldeki 5' er adet bitkide yapılmıştır.

\subsection{Morfolojik gözlemler}

Elde edilen saf hatların agro - morfolojik özelliklerinin tespiti için TPÇS (tepe püskülü çıkış süresi, gün), KÇS (koçan çıkış süresi, gün), İKY (ilk koçan yüksekliği, cm), SK (sap kalınlığı, cm), YD (yaprak dikliği, ${ }^{\circ}$ ), YS (yaprak sayısı, adet) ve YA (yaprak alanı, $\mathrm{cm}^{2}$ ) parametreleri belirlenmiş̧ir (Cömertpay, 2008; Tezel, 2007).

\subsection{Fizyolojik gözlemler}

Stoma iletkenliği porometre cihazı ile belirlenmiş, mmol. $\mathrm{m}^{2} \mathrm{~s}^{-1}$ olarak kaydedilmiştir (Özdemir, 2012). Bitkilerin KM (klorofil miktarı) değerleri Spadmetre Spad 502 cihazlyla belirlenmiş elde edilen bulgular spad olarak kaydedilmiştir (Şeflek, 2010). Klorofil flüoresans1 ölçümlerinden önce yaprakların üst yüzeyleri $30 \mathrm{dk}$ boyunca kapatılmış, ardından bitki yapraklarında bitki verim analiz cihazı "Plant Efficiency Analyser" (Hansatech Instruments Ltd.) flüometresi ile; Fo (değişken olmayan bazal klorofil flüoresansı), Fv (değişken flüoresans), Fm (maksimum flüoresans indüksiyonu) ve $\mathrm{Fv} / \mathrm{Fm}$ oranları belirlenerek kaydedilmiştir (Özdemir, 2012). Serbest prolin içeriği Bates ve ark., (1973)' a göre belirlenmiştir. Sıvı fazdan aspire edilen toluen fraksiyonu spektrofotometre de 520 nm absorbansta okunmuş, prolin konsantrasyonu, kalibrasyon eğrisinden faydalanılarak hesaplanmış ve $\mu$ mol prolin. $\mathrm{g}^{-1}$ taze ağırlık olarak kaydedilmiştir. Lipit peroksidasyonu Madhava ve Sresty (2000)' e göre TBAR reaksiyonu sonucu oluşan MDA miktarının belirlenmesi esasına göre belirlenmiş, aktivite için 532 $600 \mathrm{~nm}$ aralığında absorbans değişimlerine bakılmıştır.

\section{3. İstatistikî analiz ve değerlendirme}

Araştırmada incelenen özelliklere ait veriler SPSS 20 istatistik paket programında korelasyon analizine tabi tutulmuşlardır. 


\section{Bulgular ve Tartışma}

Konya ekolojik koşullarında 2013 yılı yetiştirme sezonunda üretilmiş 31 adet atdişi mısır hattında belirlenmiş agro - morfolojik ve fizyolojik özelliklerin olası tüm korelasyon kombinasyonlarının katsayıları Çizelge 1' de verilmiştir. Elde edilen bulgulara göre tüm korelasyon kombinasyonları içerisinde 20 adet kombinasyonun istatistiki olarak önemli olduğu görülmüştür.
Denemeye konu özellikler arasındaki korelasyon katsayısı değerleri incelendiğinde YA özelliği ile FV, KM, MDA ve YD özellikleri arasında istatistiki olarak önemli ilişkiler bulunduğu kaydedilmiştir. Fotosentetik verim ve KM özellikleri ile önemli; YD özelliği ile çok önemli ve pozitif ilişkileri olan YA karakterinin, MDA özelliği ile önemli ve negatif bir ilişkisi olmuştur [YA $\times$ $\mathrm{FV}\left(0.29^{*}\right), \mathrm{YA} \times \mathrm{KM}\left(0.26^{*}\right), \mathrm{YA} \times \mathrm{MDA}\left(\square 0.28^{*}\right)$, YA $\times$ YD $\left.\left(0.57^{* *}\right)\right]($ Çizelge 1$)$.

Çizelge 1. Atdişi mısır hatlarında belirlenmiş agronomik, morfolojik ve fizyolojik unsurların korelasyon değerleri

\begin{tabular}{llllllllllll}
\hline Parametreler & $\begin{array}{c}\text { FV } \\
(\mathrm{PE})\end{array}$ & $\begin{array}{c}\text { IKY } \\
(\mathrm{FEH})\end{array}$ & $\begin{array}{c}\text { KÇS } \\
(\mathrm{FT})\end{array}$ & $\begin{array}{c}\text { KM } \\
(\mathrm{CC})\end{array}$ & MDA & $\begin{array}{c}\text { Prolin } \\
(\text { Proline) }\end{array}$ & $\begin{array}{c}\text { SI } \\
(\mathrm{SC})\end{array}$ & $\begin{array}{c}\text { SK } \\
(\mathrm{ST})\end{array}$ & $\begin{array}{c}\text { TPÇS } \\
(\mathrm{TT})\end{array}$ & $\begin{array}{c}\text { YA } \\
(\mathrm{LA})\end{array}$ & $\begin{array}{c}\text { YD } \\
(\mathrm{LAn} \text {.) }\end{array}$ \\
\hline İKY (FEH) & $0.64^{*}$ & $\ldots$ & $\ldots$ & $\ldots$ & $\ldots$ & $\ldots$ & $\ldots$ & $\ldots$ & $\ldots$ & $\ldots$ & $\ldots$ \\
KÇS (FT) & $0.29^{*}$ & $0.55^{*}$ & $\ldots$ & $\ldots$ & $\ldots$ & $\ldots$ & $\ldots$ & $\ldots$ & $\ldots$ & $\ldots$ & $\ldots$ \\
KM (CC) & 0 & 0.11 & 0.10 & $\ldots$ & $\ldots$ & $\ldots$ & $\ldots$ & $\ldots$ & $\ldots$ & $\ldots$ & $\ldots$ \\
MDA & -0.17 & -0.16 & -0.08 & -0.01 & $\ldots$ & $\ldots$ & $\ldots$ & $\ldots$ & $\ldots$ & $\ldots$ & $\ldots$ \\
Prolin & -0.14 & -0.05 & $0.29^{*}$ & 0.13 & -0.02 & $\ldots$ & $\ldots$ & $\ldots$ & $\ldots$ & $\ldots$ & $\ldots$ \\
SI (SC) & -0.09 & -0.15 & 0.17 & 0.17 & -0.02 & -0.06 & $\ldots$ & $\ldots$ & $\ldots$ & $\ldots$ & $\ldots$ \\
SK (ST) & 0.19 & $0.55^{*}$ & 0.16 & $0.55^{*}$ & 0 & -0.03 & 0.04 & $\ldots$ & $\ldots$ & $\ldots$ & $\ldots$ \\
TPÇS (TT) & $0.31^{*}$ & $0.44^{*}$ & $0.60^{* *}$ & -0.17 & -0.19 & 0.07 & 0.16 & 0.02 & $\ldots$ & $\ldots$ & $\ldots$ \\
YA (LA) & $0.29^{*}$ & $0.55^{*}$ & 0.09 & $0.26^{*}$ & -0.28 & -0.09 & -0.0 & $0.47^{*}$ & 0.06 & $\ldots$ & $\ldots$ \\
YD (LAn.) & 0.16 & $0.32^{*}$ & -0.10 & 0.18 & -0.06 & -0.23 & -0.1 & $0.52^{*}$ & -0.29 & $0.57^{*}$ & $\ldots$ \\
YS (LN) & 0.25 & $0.32^{*}$ & 0.12 & 0.10 & -0.08 & 0 & -0.1 & 0.07 & -0.18 & $0.36^{*}$ & 0.10 \\
\hline
\end{tabular}

$* \mathrm{P}<0.01$

$* * \mathrm{P}<0.05$

FV (PE): Fotosentetik Verim [Photosynthetic Efficiency, $\left(\mathrm{Fv} \mathrm{Fm}^{-1}\right)$ ]; IKKY (FEH): İlk Koçan Yüksekliği [First Ear Height (cm)]; (FT): Koçan Çıkış Süresi [Flowering Time (gün, day)]; YS (LN): Yaprak Sayıs1 [Leaf Number (adet, number)]; KM (CC): Kl

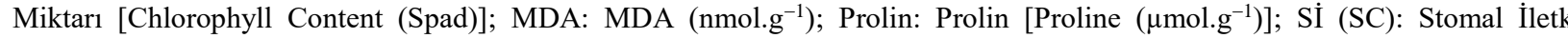
[Stomatal Conductance $\left(\mathrm{mmol}^{2} \mathrm{~m}^{-1}\right)$ ]; SK (ST): Sap Kalınlı̆ğ [Stem Thickness $(\mathrm{cm})$ ]; TPÇS (TT): Tepe Püskülü Çıkış $\mathrm{S}$ [Tasseling Time (gün, day)]; YA (LA): Yaprak Alanı [Leaf Area $\left(\mathrm{cm}^{2}\right)$ ]; YD (LAn.): Yaprak Dikliği [Leaf Angle $\left(^{\circ}\right)$ ]

Yapraklar bitkide fotosentezin yoğun olarak gerçekleştiği, bünyesinde klorofil barındıran organlardır. Dolayısıyla YA değerleri yüksek olan genotiplerin $\mathrm{KM}$ ve bununla ilintili $\mathrm{FV}$ değerlerinin yüksek olması olasıdır. Erdal (2016) yüksek fotosentetik unsurlar barındıran genotiplerin yüksek verim potansiyellerine sahip olduklarını bildirmiştir. Yaprak alanı fazla olan bir genotipin YD değerinin düşük olması yani yaprakların sapa dar bir açı ile bağlanması, söz konusu genotipin silajllk olarak geliştirilecek çeşitlere ebeveyn olabileceğine işaret edebilir. Çünkü YD' nin düsük olması s1k ekime toleransa ișaret ederken, YA' nın fazla olması yüksek yeșil ot verimine işaret eder. Yaprak açısının dar olmasının sık ekime toleransı arttırıcı etkisi silajlık çeşitler için olduğu kadar tanelik çeşitler içinde önemlidir. Sık ekime toleranslı tanelik amaçlı yetiştirilen genotiplerden yüksek girdi kullanımı ile tatminkâr verim değerleri elde etmek mümkündür. Yaprak alanı YD, İKY gibi morfolojik karakterlerin yanında FV, KM ve SI gibi fotosentetik özellikleri de uygun aralıklarda olan genotiplerin yüksek verim değerleri ile de ön plana çıktıkları bilinmektedir.

Yaprakları sapa dar açı ile bağlanan genotipler de bitkinin her noktası 1şıkla temas halinde olduğundan fotosentetik asimilasyon alanı artmış olur. $\mathrm{Bu}$ tip bitkilerin kanopi sıcaklıkları da düşüktür. Kızılgeçi ve
Albayrak (2016) kanopi sıcaklığı düşük olan genotiplerin olumsuz çevresel koşullara toleranslarının daha fazla olduğunu bildirmişlerdir.

Malondialdehitler çoklu doymamış yağ asitlerinin oksidasyonu ile oluşan ikincil metabolizma ürünleridirler (Sade ve ark., 2011). Malondialdehit miktarındaki artış bitki bünyesinde ROT (reaktif oksijen türleri) üretildiği anlamını taşır ve dolayısıyla yüksek MDA miktarının belirlendiği bir bitki organizmasında YA değerinin düşük olması muhtemeldir. İlk koçan yüksekliği özelliğinin YD ve YS özellikleri ile önemli, FV özelliği ile çok önemli ve pozitif ilişkileri olduğu belirlenmiştir [İKY $\times$ YD $\left(0.32^{*}\right)$, İKY $\times$ YS $\left(0.32^{*}\right)$, İKY $\times$ FV $\left(0.64^{* *}\right)$ ] (Çizelge 1). İlk koçan yüksekliği ve FV özellikleri arasındaki korelasyon katsayısı değerinin 0.64 olduğu tespit edilmiştir. Ayrancı ve Sade (2004), Öktem ve Çölkesen (1997) ve Elmalı ve Soylu (2008) misırda bitki boyu ve İKY özellikleri arasında önemli ve pozitif ilişkiler belirlediklerini bildirmişlerdir. Bitki boyu değerleri yüksek olan genotiplerin boğum sayılarının, dolayısıyla yaprak sayılarının daha fazla olduğunu söylemek mümkündür. Nitekim IKKY ve YS özellikleri arasındaki korelasyon da istatistiki olarak önemli ve pozitif olmuştur (Çizelge 1). Bu durumda İKY değerlerinin FV değerleri ile çok önemli ve pozitif ilişsilerinin olması da açıklanabilir ve bilimsel temelli 
bir dayanağa sahiptir. Öktem ve Çölkesen (1997) İKY ve tane verimi özellikleri arasında $\left(0.44^{*}\right)$ önemli ve pozitif ilişkiler belirlediklerini bildirmişlerdir. Yüksek İKY yüksek bitki boyuna, yüksek bitki boyu da daha fazla fotosentetik asimilasyon alanına işaret eder. Silajlık ve tanelik çeşitlerde sık ekime toleransın önemli markörü YD özelliğinin, İKY özelliği ile istatistiki olarak önemli ve YA özelliği ile istatistiki olarak çok önemli ve pozitif ilişkileri olduğu belirlenmiştir [YD $\times$ İKY $\left(0.32^{*}\right), \quad$ YD $\times$ YA $\left.\left(0.57^{* *}\right)\right]$ (Çizelge 1). Yaprakları dik olan bir genotipin ayn zamanda İKY ve YA değerlerinin yüksek olmasının genotipe gerek silaj amaçlı, gerekse tanelik amaçlı kullanımda önemli avantajlar sağlayacağı düşünülmektedir. Dik yapraklı, bitki boyu yüksek ve fazla YA' ya sahip bir genotip bol yeşil aksama sahip olması dolayısıyla daha fazla fotosentetik özümseme yapabilecektir.

\section{Sonuç}

Konya ekolojik koşullarında geliştirilmiş 31 adet atdişi mısır hattında belirlenmiş 12 agro - morfolojik ve fizyolojik karakterin korelasyon analizi sonuçlarına göre birçok korelasyon kombinasyonunun yanında YS, YA, $\mathrm{KM}$ ve FV gibi fotosentetik unsurlarında bazı özellikler ile istatistiki olarak önemli ve pozitif ilişkiler içerisinde oldukları görülmüştür. Korelasyon analizi sonuçlarına göre İKY $\times \mathrm{FV}\left(0.64^{* *}\right), \mathrm{YA} \times \mathrm{YD}\left(0.57^{* *}\right)$ özellikleri arasında çok önemli; YD $\times$ İKY $\left(0.32^{*}\right)$, YS $\times$ İKY $\left(0.32^{*}\right), \mathrm{YA} \times \mathrm{FV}\left(0.29^{*}\right), \mathrm{YA} \times \mathrm{MDA}\left(-0.28^{*}\right)$ ve YA $\times \mathrm{KM}\left(0.26^{*}\right)$ özellikleri arasında ise önemli ve anlamlı ikili ilişkiler olduğu belirlenmiştir. Söz konusu durum denemeye konu popülasyonda fotosentetik unsurlara bağglı bir seleksiyonun etkili olabileceğine ișaret etmektedir. Çalışmada birbirleri ile istatistiki olarak önemli ilişkileri bulunan çok sayıda karakter olduğu görülmektedir. $\mathrm{Bu}$ durumda az sayıda karakterin belirlenmesiyle bu karakterlerle ilintili diğer özellikler hakkında bilgi sahibi olmak mümkündür.

Çalışmadan elde edilen bulgulara göre farklı karakterlerin birbirleri ile olan ilişkilerinin belirlenmesinin ıslahçı ve araştırmacılara önemli ölçüde zaman ve işgücü tasarrufunun yanında daha fazla karakteri belirleme ve üzerinde çalıştıkları genotipleri farklı unsurlar bakımından ele alma imkânı sağlayacağı sonucuna ulaşılmıştır.

\section{Teşekkür}

$\mathrm{Bu}$ çalışma Selçuk Üniversitesi BAP Koordinatörlüğü tarafindan 13401006 numaralı proje ile desteklenmiştir.

\section{Kaynaklar}

Al-Ghamdi, A., 2009. Evaluation of oxidative stres tolerance in two wheat (Triticum aestivum L.) cultivars in response to drought. International Journal of Agriculture and Biology 1: 7-12.
Ayrancı, R., Sade, B., 2004. Konya ekolojik şartlarında yetiştirilebilecek atdişi melez misır (Zea mays L. indentata Sturt.) çeşitlerinin belirlenmesi. Bitkisel Araştırma Dergisi, 2: 6-14.

Bates, L. S., Waldren, R. P., Tear, I. D., 1973. Rapid determination of free proline for water stress studies. Plant and Soil, 39: 205-207.

Bayramoğlu, Z., Bozdemir, M., 2018. Türkiye' de üretilen mısırın ekonomik gelişim seyri. Türk Tarım Gida Bilim ve Teknoloji Dergisi, 6(8): 1092-1100.

Cömertpay, G., 2008. Yerel misır populasyonlarının morfolojik ve DNA moleküler işaretleyicilerinden SSR tekniği ile karakterizasyonu. Doktora Tezi. Çukurova Üniversitesi Fen Bilimleri Enstitüsü, 118s, Adana.

Elmalı, H., Soylu, S., 2008. Melez atdişi mısırda farklı taban gübresi çeşitlerinin tane verimi, verim unsurları ve kalite üzerine etkileri. Selçuk Tarım ve Gida Bilimleri Dergisi, 22(44): 104-112.

Erdal, Ş., 2016. Misırda normal ve kuraklık stresi koşullarında tane verimi ile ilişkili seleksiyon kriterlerinin belirlenmesi. Derim, 33(1): 131-143. doi:10.16882/derim.2016.92026

Kızılgeçi, F., Albayrak, Ö., 2016. Relationships of grain yield and some quality parameters with physiological parameters in some triticale advanced lines. In: International Engineering, Science and Education Conference, Cilt 1, 1-3, Diyarbakır.

Konuşkan, Ö., 2006. At dişi mısırda (Zea mays indentata Sturt.) diallel melez analizleri ile bazı tarımsal ve tane kalite özelliklerinin kalıtımı üzerine araştırmalar. Doktora Tezi. Çukurova Üniversitesi Fen Bilimleri Enstitüsü, 205s, Adana.

Madhava Rao, K.V., Sresty, T.V.S., 2000. Antioxidative parameters in the seedlings of pigeonpea (Cajanus cajan L. Millspaugh) in response to $\mathrm{Zn}$ and $\mathrm{Ni}$ stresses. Plant Science, 157: 113-128.

Musila, R.N., Diallo, A.O., Makumbi, D., Njoroge, K., 2010. Combining ability of early-maturing quality protein maize inbred lines adapted to eastern Africa. Field Crops Research, 119: 231-237. doi: 10.1016/j.fcr.2010.07.009

Öktem, A., Çölkesen, M. 1997. Harran ovası ikinci ürün koşullarına uygun erkenci mısır (Zea mays L.) genotiplerinn ve incelenenen özellikler aras1 ilişkilerin belirlenmesi üzerine araştırmalar. Kahramanmaraş Sütçü İmam Üniversitesi Fen ve Mühendislik Dergisi, 1: 131-143.

Özdemir, E., 2012. Ekmeklik buğday (Triticum aestivum L.)' da priming uygulamalarının fizyolojik parametreler üzerine etkileri. Yüksek Lisans Tezi. Selçuk Üniversitesi Fen Bilimleri Enstitüsü, 112 s., Konya.

Petersen, R.G., 1994. Agricultural field experiments design and analysis, Taylor \& Francis Group, 403 pp., USA.

Sade, B., Soylu, S., Palta, Ç., 2005. Melez misır çeşitlerinde tane verimi ve verim unsurları arasındaki ilişkilerin korelasyon, path ve faktör 
analizi yöntemleri ile değerlendirilmesi. Türkiye VI. Tarla Bitkileri Kongresi, 989-994, Erzurum.

Sade, B., Soylu, S., Yetim, E., 2011. Drought and oxidaitive stress. African Journal of Biotechnology, 10 (54): 11102-11109. doi: I: $10.5897 / A J B 11.1564$ Şeflek, A., 2010. Dallı darı (Panicum virgatum L.) çeşitlerinin verim, bazı morfolojik, fenolojik ve fizyolojik özelliklerinin tespiti. Yüksek Lisans Tezi. S.Ü. Fen Bilimleri Enstitüsü, 87s, Konya.
Temiz, M., G., 2004. Pamukta (Gossypium ssp.) çoklu dizi (Line $\times$ Tester) melezlerinde, tarımsal ve teknolojik özelliklerin kalıtımı üzerinde bir araştırma. Doktora Tezi. Çukurova Üniversitesi Fen Bilimleri Enstitüsü, 110s, Adana.

Tezel, M., 2007. Misirda (Zea mays L.) verim ve verim unsurları için kalıtım parametrelerinin belirlenmesi. Yüksek Lisans Tezi. S.Ü. Fen Bilimleri Enstitüsü, $128 \mathrm{~s}$,

Konya. 